\title{
Merged Municipalities, Higher Debt: On Free-Riding and the Common Pool Problem in Politics*
}

\author{
Henrik Jordahl $^{\S}$ and Che-Yuan Liang ${ }^{\#}$ \\ August 11, 2009
}

\begin{abstract}
This paper uses the Swedish municipal amalgamation reform of 1952 to study the common pool problem in politics. The amalgams were common pools and the municipalities had incentives to free-ride on their amalgam partners by increasing debt prior to amalgamation. We find that municipalities that merged in 1952 increased their debt between 1948 and 1952 when the reform could be anticipated. The increase amounted to $52 \%$ of new debt issued or $1.5 \%$ of total revenues in the merged municipalities. But contrary to the "law of $1 / n$ ", freeriding did not increase in common pool size.
\end{abstract}

Keywords: common pool, free-riding, local government amalgamation, difference-indifferences

JEL classification: D72, H73, H74, H77, R53

\footnotetext{
* We thank Alan Auerbach, Niclas Berggren, Sören Blomquist, Mikael Elinder, Pellervo Hämäläinen, Eva Mörk, Henry Ohlsson, Panu Poutvaara, Gérard Roland, Pilar Sorribas, Björn Tyrefors Hinnerich, Sune Welling Hansen, participants at the SUDSWEc conference in Uppsala, the world meeting of the Public Choice Society in Amsterdam, the Ph.D. workshop in public economics in Uppsala, the IIPF annual congress in Maastricht, seminar participants at Uppsala University, and two anonymous reviewers for valuable comments and suggestions, Sara Fogelberg, Daniel Hedblom, Benjamin Katzeff Silberstein and Odd Lyssarides for excellent research assistance, as well as the Jan Wallander and Tom Hedelius Foundation (Jordahl and Liang) and the Torsten and Ragnar Söderberg Foundations (Jordahl) for financial support.

${ }^{\S}$ Research Institute of Industrial Economics (IFN), P.O. Box 55665, SE-10215 Stockholm, Sweden; Phone: +46(0)8-6654533; Fax: +46-(0)8-6654599; E-mail: henrik.jordahl@ifn.se (corresponding author).

\# Uppsala Center for Fiscal Studies, Department of Economics, Uppsala University, P.O. Box 513, SE-75120, Uppsala, Sweden; Research Institute of Industrial Economics (IFN), P.O. Box 55665, SE-10215, Stockholm, Sweden; Phone: +46-(0)18-4711633; Fax: +46-(0)18-4711478; E-mail: che-yuan.liang@nek.uu.se.
} 


\section{Introduction}

The common pool problem arises when the costs of an activity that benefits a small group of people are shared among a larger group. An everyday example would be a dinner where two families have decided to split the bill. An opportunistic family will then enjoy a finer meal than usual - knowing that the other family has to pay "their" share of it. Fishing provides a related example of resource depletion. As long as fish stocks are a common resource, each individual fisher bears only a small part of the cost of overfishing. Olson (1965) was the first to investigate group dynamics in this collective action problem. As suggested by Tullock (1959) and Buchanan and Tullock (1962), the problem also arises in many political environments. A politician typically represents one group of voters, but has access to a common pool in the form of the total tax base of all voters. Situations of this kind could explain the occurrence of logrolling and pork barrel spending.

This paper studies the common pool problem in politics by using the particular situation that arose prior to the 1952 Swedish municipal amalgamation reform. Prior to the reform, debt financed expenditures almost exclusively benefited the own municipality, while all debt would soon be shared by all municipalities in the amalgam. Each amalgam therefore constituted a common pool area that the merging municipalities could exploit. We investigate whether such free-riding behavior occurred using a difference-in-differences strategy.

Conservative estimates indicate that the creation of a common pool increased per capita debt by SEK 13 (1952 price level), which corresponded to 52\% of new debt issued by the municipalities in the common pools or $1.5 \%$ of their revenues during this period. The effect was, however, independent of common pool size. In our interpretation, there was free-riding, but not in any refined way.

Weingast et al. (1981) are the first to formalize a common pool theory. In their set-up, there are $n$ identical districts within a common pool area. Each district is represented by a politician in the common pool council and she only cares about the benefits and costs associated with her own district. Each politician proposes a project that benefits her district. The decision process in the council is characterized by "universalism", where all projects are accepted (conceivably in one omnibus budget bill), and the projects are financed by homogeneous taxes in the common pool area. Each district then internalizes all marginal benefits from its project, but faces only $1 / \mathrm{n}$-th of its marginal costs. There are free-riding incentives that increase in $n$, and the same is true for project size, total common pool spending, and inefficiency. This relationship is usually referred to as the "law of $1 / n$ ".

Several empirical articles investigate the relationship between spending and legislature size, using the former variable to measure free-riding and the latter as a proxy for the number of districts. Most such studies support the law of 1/n, e.g., Gilligan and Matsusaka (1995, 2001), Bradbury and Crain (2001), Baqir (2002), and Bradbury and Stephenson (2003). But recently Pettersson-Lidbom (2004) reports serious empirical doubts.

As pointed out by Primo and Snyder (2008), there are also a few theoretical caveats to the law, as formulated by Weingast et al. (1981). Depending on several factors, Primo and Snyder demonstrate a possible reversal of the law of $1 / n$ for project size and total common pool spending. Most importantly, they point out that Weingast et al.'s (1981) original model takes district population $m$ as fixed when increasing the number of districts $n$. However, a 
condition that better reflects the situation in the empirical applications is that common pool population $N$ is fixed. Then $m$ depends on $n$ since $N=n^{*} m$, and when $n$ increases $m$ has to decrease, diminishing the value of district-specific local public goods. This logic works against the law of $1 / \mathrm{n}$. Primo and Snyder also show that although inefficiency generally increases in the number of districts, a pattern of more spending in larger legislatures is not necessarily a sign of this.

Another reason that the comparability of the different empirical studies and the Weingast et al. (1981) model is not so straightforward is that the model is derived under the assumptions of single-member districts and universalism. The degree to which a politician can be said to represent a district varies between electoral systems and political assemblies; it may, e.g., be greater at the national than at the local level. Still, both Weingast et al. (1981) and Primo and Snyder (2008) argue that the law of $1 / n$ is not restricted to the impact of legislature size on total spending, but can be used to understand broader political phenomena.

In this situation, with theoretical objections and mixed empirical evidence, we hope to contribute by investigating a case where the conditions were very favorable for the occurrence of a common pool problem with free-riding along the lines of the law of $1 / \mathrm{n}$. Our approach is theoretically attractive in several ways. Rather than fixed common pool areas, we have fixed district (municipality) size as required by the Weingast et al. (1981) model. Further, the politicians in each municipality represented only the constituents in their own unit. Each municipality could also issue debt without regard to the other amalgam partners' intervention.

Empirically, we gather previously unexploited data which provide significant variation in common pool size. The data also contain a large number of municipalities without common pools that can be used as a control group. Having such a control group allows us to sort out a discrete free-riding effect from a continuous free-riding effect that depends on common pool size according to the law of $1 / \mathrm{n}$. The discrete effect has to our knowledge not been investigated before.

Tyrefors Hinnerich (2009) conducts a contemporary and independent study that also investigates the common pool problem in politics using an amalgamation reform. He studies the later Swedish municipal amalgamation reform of 1963-1974. We compare the reforms of 1952 and 1963-1974 in the next section.

The paper proceeds as follows. The next section describes the three Swedish apportionment reforms of the last two centuries. It also explains why we choose to work with the 1952 reform. Section 3 outlines the identification strategy. Section 4 describes the data. Section 5 specifies the empirical specifications used to estimate the free-riding effects. Section 6 reports the regression results. The last section concludes. 


\section{Institutional background}

Through the local government reform of 1862, Sweden received a uniform administrative system with approximately 2,500 non-overlapping municipalities covering the whole country. The municipalities are the local governments we study. ${ }^{1}$ Each municipality was also classified as a rural municipality, borough, or city. ${ }^{2}$ The Municipal Administration Act, which became part of the Swedish Constitution, was also passed that year. This act gives the municipalities the right to run their own affairs (Sandalow 1971). The meaning of this right is not further specified, other than that the municipalities have to obey special legislation on some issues. Although this feature often gives the central government the upper hand in conflicts, the municipalities have much freedom in running their own projects. They also have a constitutional right to levy local income taxes, impose certain charges, and demand remuneration for benefits and services (Gustafsson 1978). The Swedish municipalities therefore became major independent economic actors.

In 1919, the Municipal Apportionment Act was passed. This act governs the procedures to be followed when local government boundaries are changed. The Universal Succession law in Paragraph 4 states that newly merged amalgams inherit the old municipalities' assets and debts. Each amalgam in future amalgamations can therefore be seen as a common pool area.

The 1862 municipal districting was based on the old parish borders and less so on functional and economical considerations. Soon the flaws became obvious as the rural municipalities could not provide for the increasing welfare demands of the citizens. Emigration from rural areas to the cities worsened the problem. In the beginning of the 1940s the legislature recognized the problem, and in June 1943 a commission was appointed to investigate possible remedies (Strömberg and Westerståhl 1984). In September 1945, the commission proposed large scale amalgamations of municipalities. The main guideline proposed was to merge small municipalities into new units with more than 2,000 citizens and more than SEK 8,000 (1945 price level) in tax base. In June 1946, a unanimous parliament approved the commission's proposal and publicly announced the reform plans. The final execution was planned to take place no later than January 1952.

During fall 1946, the county administrative boards started to work out a concrete suggestion (Wångmar 2003). In spring 1947 they presented a preliminary merging scheme to the municipalities, which now had the chance to object to the scheme and to propose other alternatives. Based on their comments, the county administrative boards revised the preliminary scheme before presenting their final proposal to the Judicial Board for Public Lands and Funds in fall 1947. After revising the county administrative boards' proposal, the Board presented its preliminary version to the local governments in spring 1948. For two years, they settled the final details together with the Home Office, before presenting a final proposal to the government, which decided in June 1950 that the new apportionment was to be executed in January 1952. This was also accomplished. Figure 1 shows a timeline of how the decision making behind the reform progressed. General elections were held in 1940, 1944, 1948, and 1952. Municipal elections were held in 1942, 1946, and 1950.

\footnotetext{
${ }^{1}$ There were also 267 districts and 24 counties.

2 The Swedish terms are "landskommun”, “köping”, and “stad”.
} 
Figure 1. Timeline on the progress of the reform

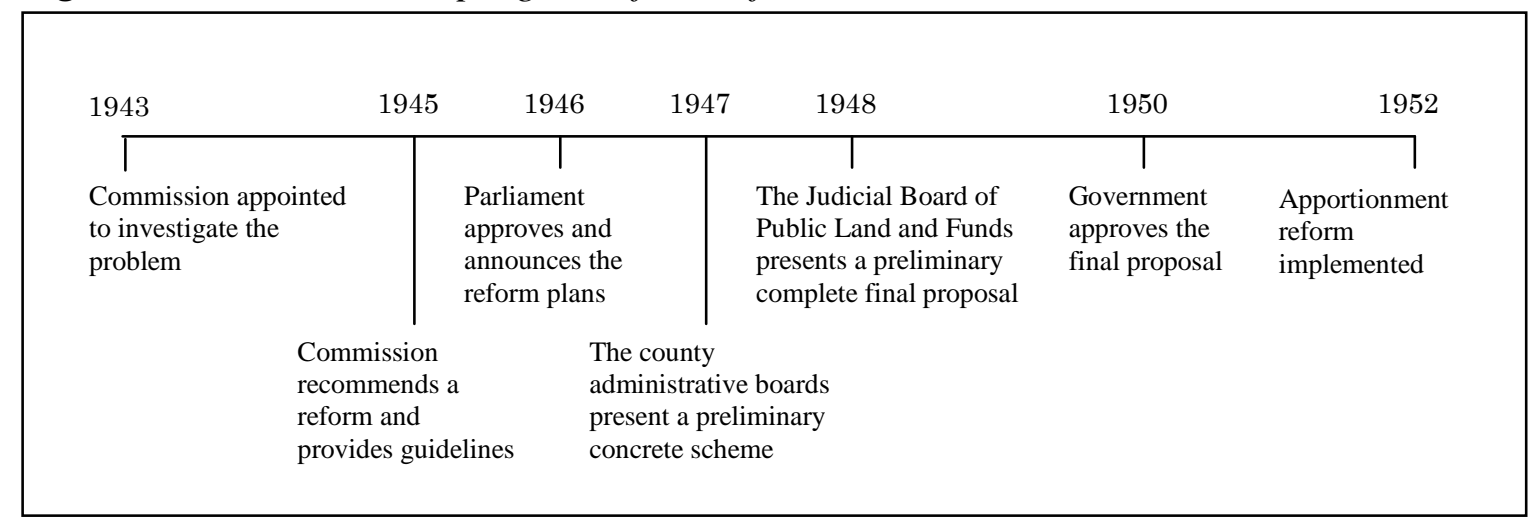

The reform reduced the number of rural municipalities from 2,284 to 823, while all 81 boroughs and 133 cities remained intact. Thus, the total number of municipalities declined from 2,498 in 1951 to 1,037 in 1952 . Three-hundred-and-four or $13.4 \%$ of the rural municipalities were unaffected by the reform. The average merger put together 4.9 municipalities. The average population increased from about 1,500 to 4,000 . The average municipal tax base more than doubled. The political administration was centralized to the largest municipality in the amalgam (Wångmar 2003). The amalgam’s new council was free to decide on the size of this new administration, although there were nationwide laws (not related to the reform) restricting the council size within certain intervals depending on municipal population. In general, the reform decreased the number of municipal representatives.

Thirty-two percent of the old municipalities had objections against the final decision in June 1950, which is about the same number that rejected the county administrative boards' preliminary scheme in spring 1947 (Wångmar 2003). Around 70\% of those objections concerned the particular composition of the amalgam whereas $30 \%$ concerned not being merged at all. Sixty-eight percent of the actual new constellations were in accordance with the county administrative boards' preliminary scheme from spring 1947. Most of the revisions, in particular the most extensive ones, took place before the Judicial Board for Public Lands and Funds' preliminary version from spring 1948. Eighty-six percent of the actual new constellations corresponded completely with this proposal. Remaining changes were small and concerned details in the composition rather than changes in whether a municipality would be merged or the approximate size of the new amalgams. In the empirical investigation we make use of this large increase in certainty about the reform and ask if municipalities that merged in 1952 started to borrow more money already in 1948.

The 1952 reform turned out to be insufficient to achieve the intended objectives (Gustafsson 1978). The growing industrialization and urbanization after the Second World War (in which Sweden did not participate) further worsened the situation of the small and shrinking municipalities. In 1959 a new commission was appointed, and in 1961 a new report suggested further amalgamations targeting 8,000 citizens as the minimum municipal size. This time functional considerations were given much higher priority (Statens Offentliga Utredningar 1978). The main guideline was to form units that were able to efficiently provide social services. 
In 1962 the new reform process started, and by 1963 the new borders were determined. One-thousand-and-six municipalities temporarily formed 282 new blocks, but the final amalgamation was voluntary. Thirty-seven municipalities, mainly cities, were unaffected by the reform. By 1969, only 38 new municipalities had been formed. The central government found the proceedings too slow and decided that the reform should be fully implemented by 1974 , and this was also achieved.

An econometric difficulty in estimating the free-riding effects is that municipalities are not merged randomly. Selection took place with respect to some observables, but probably also with respect to some unobservables causing endogeneity problems. This is a complication both in the 1952 reform and in the later one in 1963-1974. A particular endogeneity problem in the later reform is that some amalgamations were voluntary. Voluntariness could affect outcomes and the time available to exploit the common pool. The free-riding effect may also differ between voluntary and forced amalgamations. Even though it may be possible to solve these problems and interesting to sort out the effect of voluntariness, we avoid these complications by investigating the compulsory 1952 reform.

Another reason to study the reform of 1952 rather than the one of 1963-1974 is the ability to distinguish a discrete free-riding effect from the continuous one predicted by the law of $1 / \mathrm{n}$. We need merged and unmerged municipalities to examine the discrete effect and merged municipalities with different common pool size to examine the law of $1 / \mathrm{n}$. The variation in common pool size is large in both reforms, but the 1963-1974 reform only left 37 municipalities unmerged. In addition, these municipalities were almost exclusively cities whereas most of the merged municipalities were rural municipalities. There may therefore be too few and also too different unmerged municipalities to allow an estimation of the discrete effect. If there is a discrete effect which is not properly estimated or taken care of, any estimate of the continuous effect is affected. By definition, merged municipalities have larger common pools than unmerged ones, and a continuous effect estimate could pick up some of the discrete effect. In contrast, there were 304 unmerged rural municipalities in the 1952 reform, making up a large group to serve as a control for the merged municipalities. There were also many more municipalities in total in the 1952 reform.

We use borrowing, i.e., changes in debt, as our outcome variable to measure the freeriding effect. It is a variable that the municipalities could control. There were no restrictions on short-term debt and no balanced budget rules for the municipalities. Long-term debt was allowed to be issued only for investment projects and not for consumption (Gustafsson 1978). Altogether, the municipalities could change their debt from year to year for tactical reasons. It is also a clearly defined variable, documented each year. Further, a municipality's debt was difficult to misrepresent by “cooking the books". Most other asset measures are less suitable for capturing opportunistic behavior by the municipalities. 


\section{Identification strategy}

The reform was executed in January 1952. Free-riding could have started once the municipalities anticipated the reform. The incentives to free-ride depended on the degree of certainty that a reform was going to be executed, the time of execution, as well as the expectations about the new borders. The appointment of the commission in June 1943 gave the first clues about a coming reform. With the parliament's approval in June 1946, the municipalities could reasonably expect that a reform was going to be executed within six years. With the county administrative boards' preliminary scheme in spring 1947, they got the first inklings of the details. With the Judicial Board for Public Lands and Fund's proposal in spring 1948, they knew with high certainty how the new districting would look like. In June 1950, there was no uncertainty left concerning the reform.

We call the municipalities finally merged in 1952 the treated group. The "treatment" that is given to the treated municipalities is the knowledge of the amalgams (i.e., of the common pools) which were available during 1948-1952. ${ }^{3}$ The treatment group dummy, Treated, takes the value one for the treated units and zero for the untreated units. We choose to start in 1948, because the Judicial Board for Public Lands and Funds' proposal in spring 1948 marks the time when the plans turned from presumptive and with unclear details to highly certain down to the very details.

To capture every instance of free-riding, we have to go even further back in time. The first anticipations of a reform may have appeared as early as in June 1943. On the other hand, to obtain estimates that can be credibly linked to the amalgamations, we have to restrict our attention to the years where free-riding incentives were clearly in place.

The estimation of the treatment effect had been straightforward by calculating the mean difference in the outcomes between the groups during this period, or by running a bivariate ordinary least squares (OLS), had the treatment been assigned randomly. Not surprisingly, treatment was assigned based on a number of variables such as population and tax base. There is a selection problem as the two groups are not essentially similar. If we can observe all selection variables and know their relationship to the outcome variable, the selection problem could be solved by including the relevant variables as covariates. It is, however, likely that unobservable variables such as voter preferences influence the unification of political units as Alesina and Spolaore (1997), Bolton and Roland (1997), and Persson and Tabellini (2000) point out.

To account for unobservable heterogeneity, we choose a difference-in-differences (DiD) strategy. Such a strategy requires data from a pre-treatment period, i.e., data prior to 1948. As the (post-)treatment period spans four years (1948-1952) we choose the four years 19441948 as the pre-treatment period. The problem with the simple post-treatment mean difference is that it contains a heterogeneity difference in addition to the causal treatment effect difference between the groups. The intuition behind the DiD-strategy is to use the pre-treatment mean difference as a proxy for the heterogeneity difference, and remove this term from the

\footnotetext{
${ }^{3}$ In this and the next section, attention is primarily given to the intuition when the treatment effect is constant. In the regressions, we allow the treatment effect to vary with common pool size. The generalization of the intuition to this latter case is straightforward but not discussed in detail.
} 
post-treatment mean difference. In our case, this means that the estimated average treatment effect of the treated (ATT) should be interpreted as the effect of the greater certainty about the reform after 1948 compared with what could be expected before then. Since some municipalities in the coming amalgams may have started to free-ride by borrowing more money prior to 1948, the ATT constitutes a downward-biased conservative estimate of the common pool problem.

\section{Data and summary statistics}

The key assumption for DiD to identify a causal effect is the parallel trend assumption, i.e., that the heterogeneity difference between the groups is constant over time. This condition ensures that there is no important time-varying heterogeneity between the groups. With data from several points in time prior to treatment, one can assess the plausibility of this assumption by checking whether it holds in the pre-treatment period.

Based on these considerations we gather yearly panel data for the period 1944-1952 from Statistics Sweden's two publication series: Statistical Yearbooks of Administrative Districts of Sweden and Local Government Finance. We gather data on debt, population, tax base as well as on how the municipalities were merged in 1952. These data have, to our knowledge, not been used by economists previously. During this period, 71 of the 2,498 existing municipalities in the end of 1951 were involved in changes in municipality borders. These are excluded. We also exclude 33 previously rural municipalities that received borough or city status during this period. Finally, we exclude the rest of the municipalities with borough or city status in 1951 to improve the untreated control group's characteristics. ${ }^{4}$ This leaves 2,264 municipalities: 1,973 that were merged in 1952 and 291 that were not.

We use the change in per capita debt, $\Delta D e b t$, as the outcome variable in our DiD design. This flow variable is what the municipalities have considerable control over in a certain year when they decide on how much more they should borrow. To adjust for inflation, we normalize monetary figures in SEK to the 1952 price level using the consumer price index. To partial out the influence of population on debt, we work with a per capita formulation.

The per capita debt level variable, Debt, on the other hand, is a stock variable which often cannot be changed much in relative terms in a certain year. It is therefore highly dependent on history, and an unsystematic change in a certain year shifts the level for all subsequent years. The evolutions of the mean debt level for the treated and untreated municipalities are plotted in Figure 2, where start-of-the-year values are shown, and where a vertical line separates the pre- and post-treatment periods. The trends seem different between the groups in the pre-treatment period. We test this formally by estimating the difference between the groups for each of the pre-treatment years controlling for year-specific effects across the groups, and then perform an F-test of the joint null hypothesis that the differences are constant. The test gives $F(4,2263)=6.32$ when using heteroscedasticity-robust standard errors clustered at the

\footnotetext{
${ }^{4}$ Although DiD may take care of this heterogeneity as well, we do not want the two groups to differ too much as there may exist time-variant heterogeneity that $\mathrm{DiD}$ does not take care of. The treatment effect may also vary with the type of municipality. Although it would be interesting to investigate this issue, there are too few municipalities and too little variation in treatment status among the boroughs and cities to do this.
} 
municipality level (similar results are obtained with non-robust standard errors). The null hypothesis of parallel trends is therefore rejected at the $1 \%$ level for per capita debt levels.

By using the flow variable we account for the different trends in the level variable. The corresponding evolutions of the mean debt change for the treated and untreated municipalities are plotted in Figure 3. The corresponding F-test of the joint null hypothesis that the differences in the mean debt change between the two groups are constant gives $F(3,2263)=0.99$. We can therefore not reject the parallel trends assumption at the $10 \%$ level for per capita debt changes. This test is similar to placebo tests of treatment effects in any of the years in the pretreatment period and indicates that there are no such effects for changes.

We also see from Figure 3 that the mean debt change is lower for the treated municipalities in all four years during the pre-treatment period. Then something happens when we enter the post-treatment period. For three out of four years, the mean debt change is higher for the treated than for the untreated municipalities. The merging municipalities started to borrow more money.

The figures illustrate the mean difference between the groups. In the regression analysis, we also investigate if there is a treatment effect that varies with common pool size measured by the variable Ratio = the amalgam's population / municipality i's population -1 , where the figures are from the reform year 1952, which is the number of persons that each person in municipality $i$ can free-ride upon. This is a straightforward extension of the common pool measure when districts have different populations. The results are similar when using the number of amalgam partners. An implicit assumption is that the treated municipalities had correct anticipation on average about the populations at the reform date already in 1948. This is a rather weak assumption since population changes are small for such a short time period. In any case, the alternative of using the 1948 populations produces similar results.

We add control variables to account for the explicitly stated selection criteria into treatment. Those controls are: the population at the beginning of the period in thousands, Population; the percentage change in population during the period, $\Delta$ Population; the per capita tax base at the beginning of the period in thousands SEK, Taxbase; and the change in per capita tax base during the period in thousands SEK, $\triangle$ Taxbase. We also include the initial debt level (debt at the beginning of the period) as a control since it reflects previous fiscal behavior that affects current possibilities and needs of debt accumulation.

Summary statistics are reported in Table 1. Means are reported for the treated and untreated municipalities in the pre- and post-treatment periods. We see that an average treated municipality was merged with other municipalities with 6.6 times its own population. The merged municipalities had lower values on almost all variables both before and after they received treatment, reflecting the selection criteria. Several variables also increased between the periods reflecting the development over time. 
Figure 2. Evolution of mean debt between 1944 and 1952

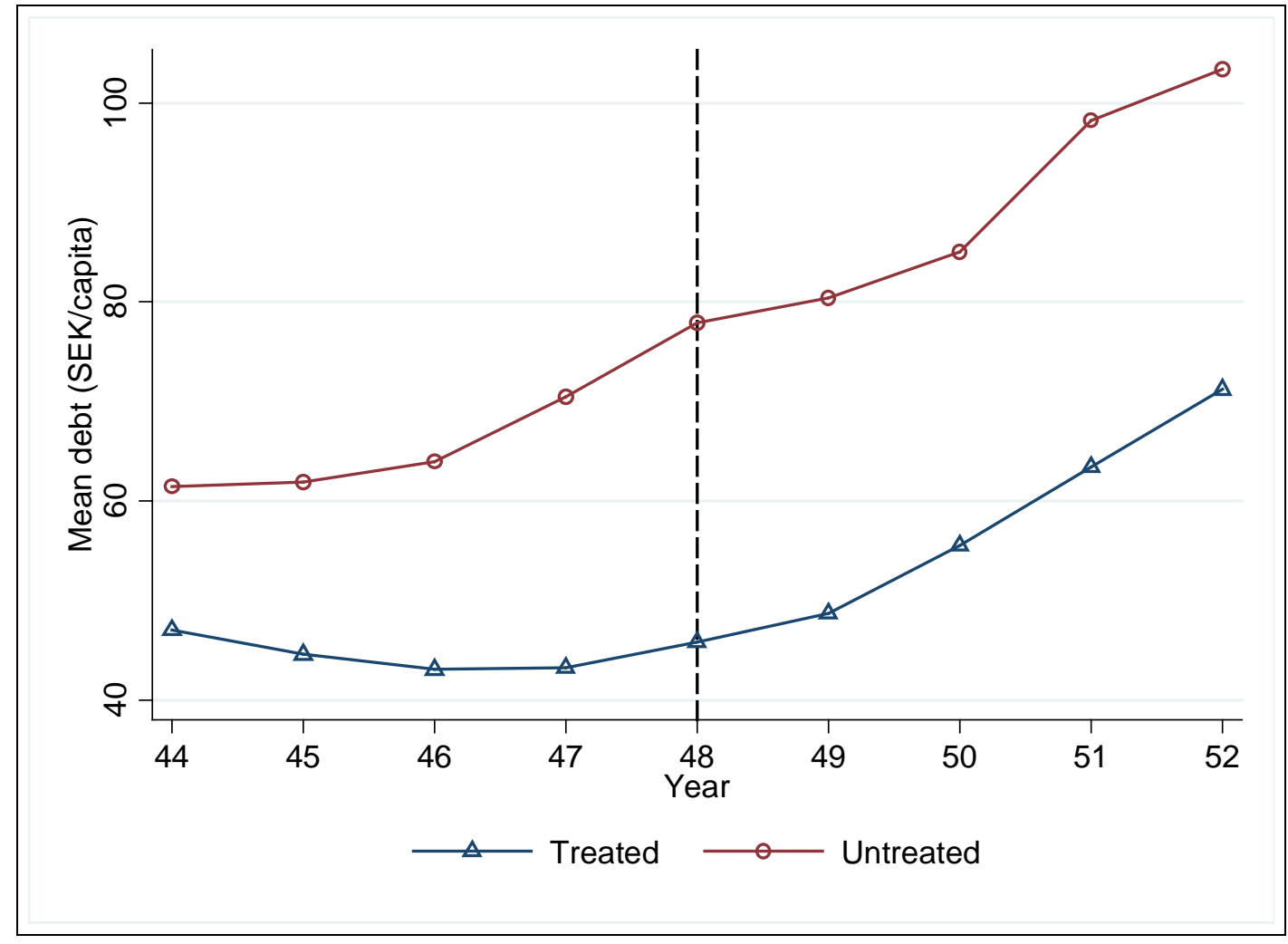

Figure 3. Evolution of mean debt change between 1944 and 1952

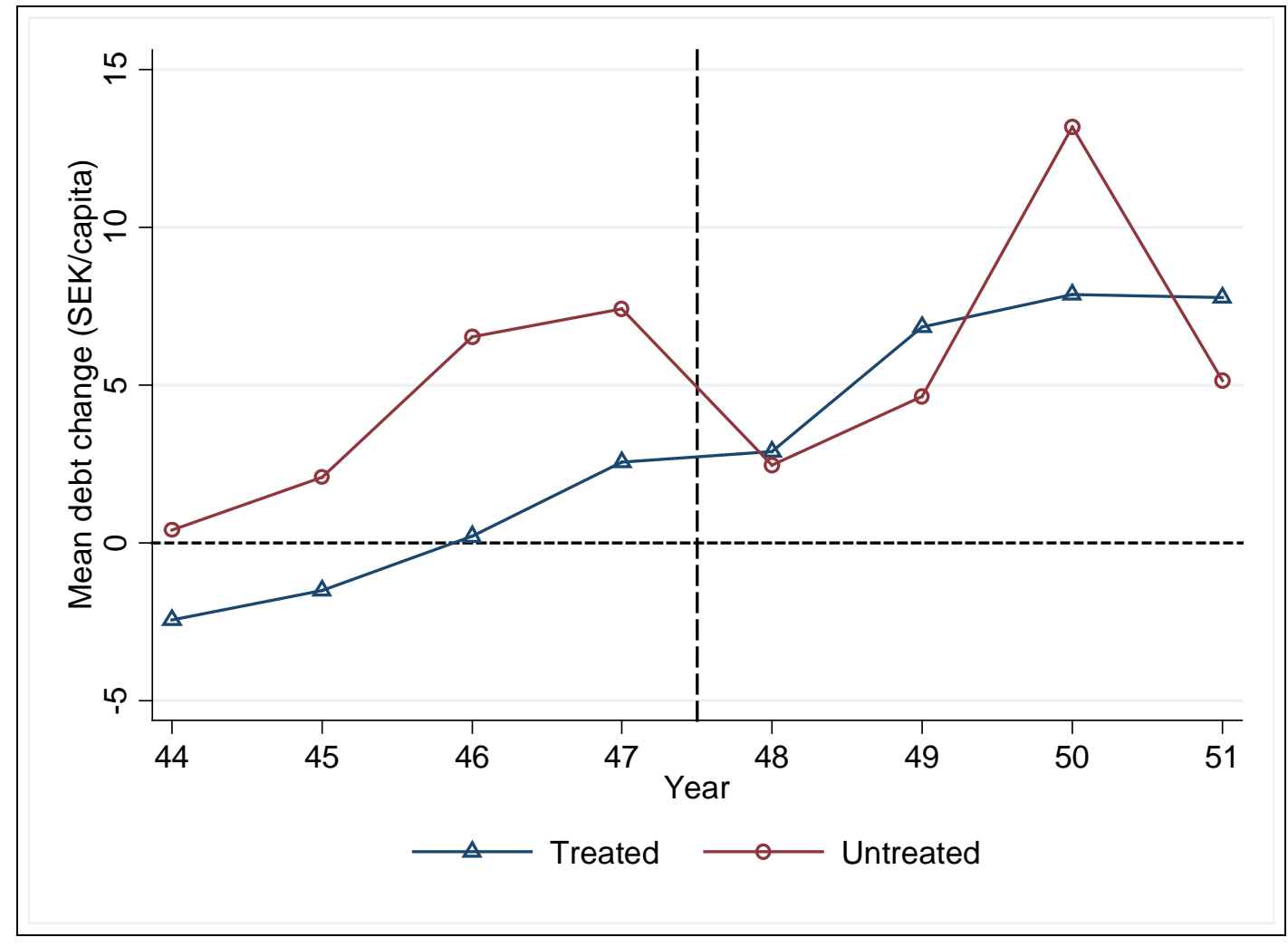


Table 1. Summary statistics: variable means

\begin{tabular}{l|cc|cc}
\hline Group & \multicolumn{2}{|c|}{ Treated } & \multicolumn{2}{c}{ Untreated } \\
Period & Pre-treatment & Post-treatment & Pre-treatment & Post-treatment \\
\hline Treated & 1.000 & 1.000 & 0.000 & 0.000 \\
Ratio & 6.618 & 6.618 & 0.000 & 0.000 \\
Debt & 47.012 & 45.793 & 61.466 & 77.919 \\
$\Delta$ Debt & -1.219 & 25.397 & 16.453 & 25.441 \\
Population & 1.087 & 1.063 & 4.213 & 4.252 \\
$\Delta$ Population & -0.035 & -0.023 & 0.011 & 0.012 \\
Taxbase & 1.015 & 1.608 & 1.168 & 1.858 \\
$\Delta$ Taxbase & 0.593 & 0.475 & 0.690 & 0.339 \\
\hline
\end{tabular}

Notes: 1,973 municipalities are treated and 291 untreated.

\section{Empirical specification}

We start with a two-period specification by merging the four pre-treatment years in a first period and the four post-treatment years in a second. This is one of the measures to account for serial correlation recommended by Bertrand et al. (2004). Technically, the DiD-strategy can be implemented in different ways all producing the same point estimate. We use a standard interaction term specification. First, we estimate the discrete treatment effect by estimating the following specification with OLS:

$$
\Delta \text { Debt }_{i, t}=\beta_{0}+\beta_{T} \text { Treated }_{i}+\beta_{P} \text { Post }_{t}+\beta_{T P} \text { Treated }_{i} \text { Post }_{t}+\boldsymbol{\beta}_{z}^{\prime} \mathbf{z}_{i, t}+\varepsilon_{i, t},
$$

where $i$ indexes municipalities, and $t$ indexes the two time periods. In the pre-treatment period 1944-1948, $t=0$, and in the post-treatment period 1948-1952, $t=1$. The post-treatment period dummy, Post $t_{t}$ takes the value zero when $t=0$ and one when $t=1$. The interaction term, Treated $_{i}$ Post $_{t}$, takes the value one if treatment has been given to a municipality and zero otherwise. Treatment is given to the treated municipalities in the post-treatment period by the assignment of a common pool in terms of a future amalgam. The vector of control variables,

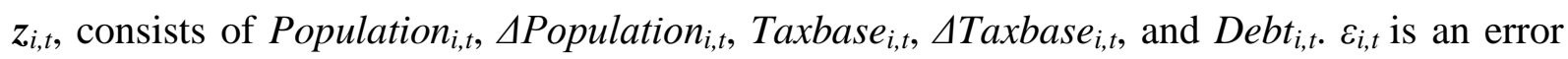
term, and we assume that it is uncorrelated with Treated $_{i}$ Post $_{t}$ conditional on the other regressors, i.e., $E\left(\varepsilon_{i, t} \mid\right.$ Treated $_{i}$ Post $_{t}$, Treated $_{i}$, Post $\left._{t}, \mathbf{z}_{i, t}\right)=E\left(\varepsilon_{i, t} \mid\right.$ Treated $_{i,}$, Post $\left._{t}, \mathbf{z}_{i, t}\right)$. $\beta_{0}$ is a constant. $\beta_{T P}$ is the DiD-estimate ${ }^{5}$ of the discrete treatment effect, which is the average treatment effect (ATT) of the treated.

\footnotetext{
${ }^{5}$ Another specification that implements the DiD-strategy is to use the fixed effect estimator on

$$
\Delta \text { Debt }_{i, t}=\beta_{P} \text { Post }_{t}+\beta_{T P} \text { Treated }_{i} \text { Post }_{t}+\boldsymbol{\beta}_{z}^{\prime} \mathbf{z}_{i, t}+v_{i}+\varepsilon_{i, t},
$$

where $v_{i}$ is the unit fixed effect. This is more general as it explicitly allows municipality specific, rather than group specific, heterogeneity. However, either specification gives the same DiD-point estimate. The reason is that all municipality specific heterogeneity affects the interaction term through the group-specific heterogeneity term. Standard errors differ however, although not much here. When no controls are included, the DiD point estimate can also be calculated using the following formula reflecting the intuition behind the method:
}

$$
\beta_{T P}=\left[\overline{\Delta D e b t}_{\text {Treated }=1, \text { Post }=1}-\overline{\Delta D e b t}_{\text {Treated }=0, \text { Post }=1}\right\rfloor-\left[\overline{\Delta D e b t}_{\text {Treated }=1, \text { Post }=0}-\overline{\Delta D e b t}_{\text {Treated }=0, \text { Post }=0}\right\rfloor
$$


From the specification in equation (1), we see why the DiD-strategy is attractive. Any time-invariant heterogeneity between the treated and the untreated groups and any groupinvariant heterogeneity over time are removed by the second and the third terms. Now, groupspecific time-varying factors may still bias the DiD-estimate. This is the case if the groups have properties that affect the dependent variable that are correlated with receiving treatment and that change over time. This is the regression-framework way of saying that the parallel trend assumption may not hold. The fact that the parallel trend assumption holds in the pretreatment period (as shown in the previous section) is a strong indication that it holds also in the post-treatment period, but there is always a risk that this is not the case. The problem is of major concern when using repeated cross sections as the groups in the pre-treatment and posttreatment periods may not have been selected in the same way. It is still a concern when using a panel as group properties may change over time. It is common to add time- and groupvarying control variables to account for this.

It is important to include only predetermined control variables that are not affected by the treatment since non-predetermined controls affected by the treatment could bias the DiDestimate by absorbing indirect treatment effects working through those controls (Rosenbaum 1994; Rubin 2004). We include population and tax base variables as the selection into treatment were explicitly stated to be based on these variables. They are also commonly viewed as predetermined variables, and arguably, any treatment effect that works through these variables is not a free-riding effect. Additionally, we include the initial debt level as it reflects previous fiscal behavior that affects current possibilities and needs of debt accumulation. There are significant differences in debt levels between treated and untreated municipalities according to Figure 2 and these differences may remain even once other municipality characteristics have been partialled out.

Next, we proceed to allow for a continuous treatment effect. We replace the discrete treatment group variable Treated $_{i}$ with the continuous variable Ratio ${ }_{i}$. This specification with a continuous treatment effect restricted to follow the law of $1 / n$ looks like:

$$
\Delta \text { Debt }_{i, t}=\beta_{0}+\beta_{R} \text { Ratio }_{i}+\beta_{P} \text { Post }_{t}+\beta_{R P} \text { Ratio }_{i} \text { Post }_{t}+\boldsymbol{\beta}_{z}^{\prime} \mathbf{z}_{i, t}+\varepsilon_{i, t} .
$$

The relevant heterogeneity is now different between municipalities with different common pools and the relevant time-invariant heterogeneity term to include is Ratio ${ }_{i}$. Equation (2) is a straightforward modification of the discrete specification in equation (1). $\beta_{R P}$ is now the measure of free-riding, which should be larger than zero according to the prediction of the law of $1 / n$.

$\beta_{R P}$ in equation (2) could be biased if the continuous effect is not the only free-riding effect, as it may interact with a discrete effect. We therefore also estimate a general treatment effect specification allowing for both a discrete and a continuous effect: ${ }^{6}$

$$
\begin{aligned}
\Delta \text { Debt }_{i, t}= & \beta_{0}+\beta_{T} \text { Treated }_{i}+\beta_{R} \text { Ratio }_{i}+\beta_{P} \text { Post }_{t}+ \\
& \beta_{\text {TP }} \text { Treated }_{i} \text { Post }_{t}+\beta_{R P} \text { Ratio }_{i} \text { Post }_{t}+\boldsymbol{\beta}_{z}^{\prime} \mathbf{z}_{i, t}+\varepsilon_{i, t} .
\end{aligned}
$$

\footnotetext{
${ }^{6}$ We can implement a DiD using fixed effects specifications instead of equation (2) and (3) as well. With municipality fixed effects, we have to drop the time-invariant covariates. Again, only standard errors are affected by this.
} 
$\beta_{T P}$ is now an estimate of the discrete free-riding effect (rather than the ATT) whereas $\beta_{R P}$ is an estimate of the continuous effect less the interaction with the discrete effect. The ATT can be retained from this specification as $\beta_{T P}+\beta_{R P}$ Mean $\left(\right.$ Ratio $_{i} \mid$ Treated $\left._{i}=1\right)$.

We also estimate year-specific treatment effects within the post-treatment period, which allow us to investigate the dynamics. This can be estimated by using yearly data and by replacing the post-treatment period dummy with year dummies for each of the post-treatment years. Equations (1) to (3) now generalize to:

$$
\begin{aligned}
\Delta \text { Debt }_{i, t}= & \beta_{0}+\beta_{T} \text { Treated }_{i}+\boldsymbol{\beta}_{P}^{\prime} \text { Post }_{t}+\beta_{T P} \text { Treated }_{i} \text { Post }_{t}+\boldsymbol{\beta}_{z}^{\prime} \mathbf{z}_{i, t}+\varepsilon_{i, t}, \\
\Delta \text { Debt }_{i, t}= & \beta_{0}+\beta_{R} \text { Ratio }_{i}+\boldsymbol{\beta}_{P}^{\prime} \text { Post }_{t}+\beta_{R P} \text { Ratio }_{i} \text { Post }_{t}+\boldsymbol{\beta}_{z}^{\prime} \mathbf{z}_{i, t}+\varepsilon_{i, t}, \\
\Delta \text { Debt }_{i, t}= & \beta_{0}+\beta_{T} \text { Treated }_{i}+\beta_{R} \text { Ratio }_{i}+\boldsymbol{\beta}_{P}^{\prime} \text { Post }_{t}+ \\
& \boldsymbol{\beta}_{T P}^{\prime} \text { Treated }_{i} \text { Post }_{t}+\boldsymbol{\beta}_{T P}^{\prime} \text { Ratio }_{i} \text { Post }_{t}+\boldsymbol{\beta}_{z}^{\prime} \mathbf{z}_{i, t}+\varepsilon_{i, t} .
\end{aligned}
$$

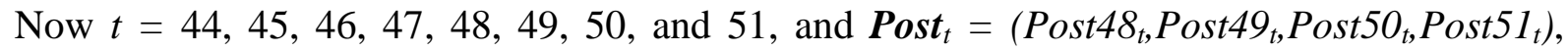
where $P$ Post $X_{t}$ is a year dummy for $X=48,49,50$, and $51 .^{7}$

\section{Results}

The two-period results are reported in Table 2. Heteroscedasticity-robust standard errors allowing for clustering at the municipality level are reported in parentheses throughout the paper. The regression estimates from equations (1) to (3), with only the discrete treatment varia${\text { ble } \text { Treated }_{i} \text {, only the continuous treatment variable Ratio }}_{i}$, and both treatment variables, are reported in the columns ATT, Law of $1 / n$, and General respectively.

The interaction term estimates are the treatment effect estimates. With only a binary treatment variable, the point estimate can be interpreted as the ATT. We find a positive ATT which is statistically significant at the $5 \%$ level. The point estimate is SEK 13.3 per capita (1952 price level) with control variables, which is a bit lower than without controls. For the treated municipalities, this corresponds to $29.1 \%$ of their debt in the beginning of the posttreatment period, $52.4 \%$ of new debt issued, and $1.5 \%$ of their revenues during this period. The ATT is economically significant.

When including only a continuous treatment term, the treatment effect estimate is the effect for each additional common pool population equal to the municipality's own population. Two intrinsic assumptions are that the common pool size has a proportional effect and the absence of other kinds of effects; assumptions that follow from the law of $1 / n$, which also predicts the effect to be positive. We find a negative effect which is statistically significant at the $1 \%$ level. The point estimate is larger with control variables: SEK -0.47 . We therefore reject the null that the effect is positive, which is predicted by the law of $1 / n$ (when restricting the functional form of the effect according to it). Since the average merged municipality was merged with other municipalities 6.6 times its own size, this gives an average effect of SEK -3.1 per capita for them, which is much smaller than the ATT. The continuous effect is small.

\footnotetext{
${ }^{7}$ Including year dummies for the pre-treatment years does not change point estimates, but affects precision.
} 
Table 2. Two-period estimates

\begin{tabular}{|c|c|c|c|c|c|c|}
\hline \multirow{2}{*}{ Dep: $\Delta$ Debt $_{i, t}$} & \multicolumn{3}{|c|}{ Without Controls } & \multicolumn{3}{|c|}{ With Controls } \\
\hline & ATT & Law of $1 / n$ & General & ATT & Law of $1 / n$ & General \\
\hline & $\begin{array}{c}17.628^{* * *} \\
(5.785)\end{array}$ & & $\begin{array}{c}2^{21.081^{* * * *}}(5.901)\end{array}$ & $\begin{array}{c}13.320^{* *} \\
(5.357)\end{array}$ & & $\begin{array}{c}16.861^{* * *} \\
(5.459)\end{array}$ \\
\hline Ratio $_{\mathrm{i}}$ Post $_{\mathrm{t}}$ & & $\begin{array}{c}-0.406^{* * *} \\
(0.147)\end{array}$ & $\begin{array}{c}-0.522^{* * * *} \\
(0.161)\end{array}$ & & $\begin{array}{c}-0.474^{* * *} \\
(0.155)\end{array}$ & $\begin{array}{c}-0.561^{* * *} \\
(0.166)\end{array}$ \\
\hline Treated $_{i}$ & $\begin{array}{c}-17.672^{* * *} \\
(3.733)\end{array}$ & & $\begin{array}{c}-16.679^{* * *} \\
(3.775)\end{array}$ & $\begin{array}{l}-4.798 \\
(5.316)\end{array}$ & & $\begin{array}{c}-6.056 \\
(5.291)\end{array}$ \\
\hline Ratio $_{\mathrm{i}}$ & & $\begin{array}{c}-0.242^{* * *} \\
(0.085)\end{array}$ & $\begin{array}{l}-0.150^{*} \\
(0.086)\end{array}$ & & $\begin{array}{c}-0.079 \\
(0.080)\end{array}$ & $\begin{array}{c}-0.038 \\
(0.080)\end{array}$ \\
\hline Post $_{t}$ & $\begin{array}{l}8.988^{*} \\
(5.356)\end{array}$ & $\begin{array}{c}26.693^{* * * *} \\
(2.238)\end{array}$ & $\begin{array}{l}8.988^{*} \\
(5.357)\end{array}$ & $\begin{array}{l}9.325^{*} \\
(5.079)\end{array}$ & $\begin{array}{c}23.833^{* * * *} \\
(2.488)\end{array}$ & $\begin{array}{c}9.503^{*} \\
(5.077)\end{array}$ \\
\hline Population $_{\mathrm{i}, \mathrm{t}}$ & & & & $\begin{array}{l}3.220^{* *} \\
(1.473)\end{array}$ & $\begin{array}{l}2.509^{* *} \\
(1.209)\end{array}$ & $\begin{array}{c}2.766^{*} \\
(1.522)\end{array}$ \\
\hline$\Delta$ Population $_{\mathrm{i}, \mathrm{t}}$ & & & & $\begin{array}{l}81.985^{* * *} \\
(19.258)\end{array}$ & $\begin{array}{l}79.072^{* * *} \\
(19.372)\end{array}$ & $\begin{array}{l}78.301^{* * *} \\
(19.298)\end{array}$ \\
\hline Taxbase $_{i, t}$ & & & & $\begin{array}{l}5.936^{* *} \\
(2.448)\end{array}$ & $\begin{array}{l}6.096^{* *} \\
(2.438)\end{array}$ & $\begin{array}{l}6.125^{* *} \\
(2.445)\end{array}$ \\
\hline$\Delta$ Taxbase $_{i, t}$ & & & & $\begin{array}{l}5.509^{* *} \\
(2.753)\end{array}$ & $\begin{array}{l}7.122^{* *} \\
(2.777)\end{array}$ & $\begin{array}{l}6.253^{* *} \\
(2.753)\end{array}$ \\
\hline Debt $_{i, t}$ & & & & $\begin{array}{c}-0.165^{* * *} \\
(0.031)\end{array}$ & $\begin{array}{c}-0.170^{* * *} \\
(0.030)\end{array}$ & $\begin{array}{c}-0.167^{* * *} \\
(0.030)\end{array}$ \\
\hline $\mathrm{R}^{2}$ & 0.03 & 0.04 & 0.04 & 0.07 & 0.07 & 0.07 \\
\hline
\end{tabular}

Notes: 4,528 observations are used in each regression. Heteroscedasticity-robust standard errors allowing for clustering within municipalities are reported in parentheses. ${ }^{*}$ significant at $10 \%$; ${ }^{* *}$ significant at $5 \%$; ${ }^{* * *}$ significant at $1 \%$.

When including only a continuous treatment term, the treatment effect estimate is the effect for each additional common pool population equal to the municipality's own population. Two intrinsic assumptions are that the common pool size has a proportional effect and the absence of other kinds of effects; assumptions that follow from the law of $1 / n$, which also predicts the effect to be positive. We find a negative effect which is statistically significant at the $1 \%$ level. The point estimate is larger with control variables: SEK -0.47. We therefore reject the null that the effect is positive, which is predicted by the law of $1 / n$ (when restricting the functional form of the effect according to it). Since the average merged municipality was merged with other municipalities 6.6 times its own size, this gives an average effect of SEK -3.1 per capita for them, which is considerably smaller than the ATT. The continuous effect is small.

When including both a binary and a continuous treatment term, the treatment effect estimate of the binary variable reflects a discrete effect as a municipality is treated (and not the ATT), and the continuous variable reflects a continuous effect as the common pool size increases. This general model removes the correlation between the discrete and the continuous effects. We find a discrete effect of SEK 16.9 per capita and a continuous effect of SEK -0.56 per capita, both statistically significant at the $1 \%$ level, when including controls. The ATT can be retained as $\beta_{T P}+\beta_{R P}$ Mean $\left(\right.$ Ratio $_{i} \mid$ Treated $\left._{i}=1\right)$ and accords with the previous ATT estimate. The major part of the ATT therefore consists of a discrete effect. The continuous effect is still negative, and we reject the law of $1 / n$, even with this specification. In sum, we find a free-riding effect in municipalities with a common pool, although this effect does not depend on common pool size. 
The estimates of Treated $_{i}$ and Ratio ${ }_{i}$ are estimates of the unobserved heterogeneity between the groups and the estimates of Post $t_{t}$ an estimate of the heterogeneity over time. These estimates are of the same order as the treatment effect estimates and all statistically significant, when no controls are included. There are therefore important differences between the groups and over time. The differences are, however, much smaller, and generally not statistically significant, when controls are included. This indicates that the controls absorb the differences well, which is not surprising as they form the basis for the selection into treatment.

The estimates of the controls are generally statistically significant. The effects of the population and tax base variables are positive, reflecting greater opportunities to borrow in larger and wealthier municipalities. The effect of the initial debt level is negative, reflecting fewer opportunities and needs in municipalities that have already accumulated a lot of debt. Despite their effects on the dependent variable, the controls do not adjust the treatment effect estimates very much. The coefficient of determination is around 0.04 without controls and roughly doubled with controls.

Now we turn to the specifications in equations (4) to (6) which allow for year-specific treatment effects. The results from these regressions, including controls, are reported in Table 3. We report only the interaction terms that capture the treatment effects, and we leave out the heterogeneity terms between the groups and over time as well as the controls.

Table 3. Year-specific treatment estimates

\begin{tabular}{l|ccc}
\hline Dep: $\Delta$ Debt $_{\mathrm{i}, \mathrm{t}}$ & ATT & Law of $1 / \mathrm{n}$ & General \\
\hline Treated $_{\mathrm{i}}{\text { Post } 48_{\mathrm{t}}}^{*}$ & $4.639^{* * *}$ & & $5.100^{* * *}$ \\
Treated $_{\mathrm{i}}$ Post $49_{\mathrm{t}}$ & $(1.637)$ & & $(1.644)$ \\
& $6.274^{* *}$ & & $6.584^{* *}$ \\
Treated $_{\mathrm{i}}$ Post50 $_{\mathrm{t}}$ & $(2.804)$ & & $(2.856)$ \\
& -1.265 & & -0.223 \\
Treated $_{\mathrm{i}}$ Post51 $_{\mathrm{t}}$ & $(3.240)$ & & $(3.287)$ \\
& $6.445^{* *}$ & & $8.328^{* *}$ \\
Ratio $_{\mathrm{i}}$ Post48 $_{\mathrm{t}}$ & $(3.092)$ & -0.044 & $(3.232)$ \\
Ratio $_{\mathrm{i}}$ Post49 $_{\mathrm{t}}$ & & $(0.053)$ & -0.071 \\
Ratio $_{\mathrm{i}}$ Post50 $_{\mathrm{t}}$ & & -0.014 & $(0.055)$ \\
Ratio $_{\mathrm{i}}$ Post51 $_{\mathrm{t}}$ & & $(0.061)$ & -0.050 \\
& & $-0.162^{* * *}$ & $(0.065)$ \\
\hline
\end{tabular}

Notes: The same control variables as in Table 2 are included in the regressions, but omitted in the table. 18,112 observations are used in each regression. Heteroscedasticity-robust standard errors allowing for clustering within municipalities are reported in parentheses. ${ }^{*}$ significant at $10 \%$; $^{* *}$ significant at $5 \%{ }^{* * *}$ significant at $1 \%$.

We see that the ATT is around SEK 5 per capita for 1948, 1949, and 1951 and statistically significant at the 5\% level in each case. 1948 is the first treatment year, 1949 is one year prior to the municipal elections, and 1951 the last treatment year. Surprisingly, the ATT is somewhat negative, but not statistically significant, in 1950. The ATT for the whole post-treatment period can be obtained by adding the yearly effects and is close to the SEK 13.3 per capita obtained in the two-period specification. 
There are larger negative continuous treatment effects in 1950 and 1951 in the column labeled Law of $1 / n$. Since the details of the reform became known with a high degree of certainty, these are the years where positive continuous effects are most likely to appear according to the law of 1/n. Yet, both in 1950 and in 1951, we can reject such positive effects (using a one-sided hypothesis) at the $5 \%$ level.

The general specification confirms the previous results. The ATT is composed mainly of positive discrete effects in three of the post-treatment years, and there are small negative continuous effects in the last two post-treatment years.

The variation in effects over the four post-treatment years could be related to an election cycle lasting four years. However, the effects cannot be pure election cycle effects as there are no signs of such effects in the previous cycle during the pre-treatment period. Still, free-riding on the other municipalities in a common pool may have been more attractive or politically feasible in some phases of an election cycle.

One possible reason why we reject the law of $1 / \mathrm{n}$ may be that it holds only for certain common pool sizes, i.e., the continuous effect may vary with common pool size. To investigate this possibility, we divide the treated sample into three groups, with Ratio ${ }_{i}$ within different non-overlapping intervals. We choose the three intervals $0-2,2-6$ and $>6$. We then estimate the effect of the continuous treatment variable in each of these groups, using the twoperiod specification in equation (2). The results are reported in Table 4. The number of observations, the average common pool size, and the average continuous treatment effect (calculated as the continuous effect times the average common pool size for each group) are also reported.

Table 4. Differential continuous treatment effect estimates

\begin{tabular}{l|ccc}
\hline Dep: $\Delta$ Debt $_{i, t}$ & $0<$ Ratio $_{\mathrm{i}} \leq 2$ & $2<$ Ratio $_{\mathrm{i}} \leq 6$ & Ratio $_{\mathrm{i}}>6$ \\
\hline Ratio $_{\mathrm{i}}$ Post $_{\mathrm{t}}$ & 7.433 & -3.244 & $-0.385^{* *}$ \\
& $(7.575)$ & $(3.404)$ & $(0.170)$ \\
\hline Municipalities & 560 & 756 & 657 \\
Average Ratio & & 3.706 & 14.741 \\
Average Effect & 1.018 & -12.022 & -5.675 \\
\hline
\end{tabular}

Notes: The same control variables as in Table 2 are included in the regressions, but omitted in the table. Heteroscedasticity-robust standard errors allowing for clustering within municipalities are reported in parentheses. significant at $10 \% ;{ }^{* *}$ significant at $5 \% ;{ }^{* * *}$ significant at $1 \%$.

The treatment effect is statistically significant for the municipalities with the largest common pools $\left(\right.$ Ratio $\left._{i}>6\right)$. These are the least populous pre-treatment municipalities. The effect is, however, negative, and close to the full sample estimates. We find a positive effect for the municipalities with the smallest common pools $\left(0<\right.$ Ratio $\left._{i} \leq 2\right)$, but this effect is not statistically significant. Even if the point estimate SEK 7.4 per capita is large, the average effect in this group is only SEK 7.6 per capita and small relative to the discrete effect of SEK 16.9 per capita for the full sample (see Table 2). There are therefore no important effects that increase with common pool size, for any common pool size. 


\section{Conclusions}

The Swedish municipal amalgamation reform of 1952 is well suited for studying the common pool problem in politics. Municipalities that would be merged had incentives to increase their debt prior to amalgamation, and such incentives grew with common pool size in line with Weingast et al.'s (1981) law of 1/n. We find that merged municipalities increased their debt during the four years before the reform (1948-1952) in which the amalgams could be anticipated with a high degree of certainty. But the increase is independent of common pool size, contrary to what the law of $1 / n$ predicts.

The size of the debt increase is large enough to raise the issue of central government intervention in local government amalgamations. The risk of free-riding may inhibit voluntary amalgamations, and amalgamations that are decided at higher levels of government may need to follow strict procedures to prevent efficiency losses resulting from opportunistic behavior.

It is possible that there had been underinvestment in the merging municipalities. The increase in debt could then have been corrective rather than distortive, even if it would have been driven by free-riding. To question the free-riding interpretation, one could further argue that the effect better reflects concerted efforts to deal with such previous underinvestment in the merging municipalities. In view of the difficulty of measuring underinvestment, this objection must, however, remain speculative. At the very least, the financing of new projects was shifted to the common pools.

In our interpretation, the results provide evidence of uncomplicated free-riding behavior that does not vary with common pool size. It could be rationalized on several grounds. If politicians realize that there is a free-riding opportunity, but do not realize exactly what the optimal amount is, the resulting effect could be independent of common pool size. Or if the possibilities to act opportunistically were limited to a few - perhaps larger - projects, it may not have been possible to fine tune the amount of outstanding debt to the desired level.

In any case, the lack of a 1/n pattern in the clear-cut situation brought about by the Swedish amalgamation reform of 1952 calls for caution when applying the law to other less typical cases. We therefore advise further empirical studies of the common pool problem to consider the possibility of a less elaborated free-riding effect. 


\section{References}

Alesina, A., \& Spolaore, E., 1997. On the number and size of nations. Quarterly Journal of Economics, 112, 1027-1056.

Baqir, R., 2002. Districting and government overspending. Journal of Political Economy, 110, 1318-1354.

Bertrand, M., Duflo, E., \& Mullainathan, S., 2004. How much should we trust differences-indifferences estimates? Quarterly Journal of Economics, 119, 249-275.

Bolton, P., \& Roland, G., 1997. The breakup of nations: A political economy analysis. Quarterly Journal of Economics, 112, 1058-1090.

Bradbury, J. C., \& Crain, M., 2001. Legislative organization and government spending: Cross-country evidence. Journal of Public Economics, 82, 309-325.

Bradbury, J. C., \& Stephenson, F., 2003. Local government structure and public expenditures. Public Choice, 115, 185-198.

Buchanan, J., \& Tullock, G., 1962. The Calculus of Consent: Logical Foundations of Constitutional Democracy. Ann Arbor: University of Michigan Press.

Gilligan, T., \& Matsusaka, J., 1995. Deviations from constituent interests: The role of legislative structure and political parties in the States. Economic Inquiry, 33, 383-401.

Gilligan, T., \& Matsusaka, J., 2001. Fiscal policy, legislature size, and political parties: Evidence from state and local governments in the first half of the 20th century. National Tax Journal, 54, 57-82.

Gustafsson, A., 1978. Local Government in Sweden. Stockholm: Liber.

Olson, M., 1965, The Logic of Collective Action. Cambridge: Harvard University Press.

Persson, T., \& Tabellini, G., 2000. Political Economics: Explaining Economic Policy. Cambridge: MIT Press.

Pettersson-Lidbom, P., 2004. Does the size of the legislature affect the size of government? Evidence from two natural experiments. VATT Discussion Paper 350, Government Institute of Economic Research, Helsinki.

Primo, D., \& Snyder, J., 2008. Distributive politics and the law of 1/n. Journal of Politics, 70, 477-486.

Rosenbaum, P. R., 1984. The consequences of adjustment for a concomitant variable that has been affected by the treatment. Journal of the Royal Statistical Society Series A, 147, 656-666.

Rubin, D. B., 2004. Direct and indirect causal effects via potential outcomes. Scandinavian Journal of Statistics, 31, 161-170.

Sandalow, T., 1971. Local government in Sweden. American Journal of Comparative Law, 19, 766-785.

Statens Offentliga Utredningar, 1978. Ny Indelningslag för Kommuner, Landstingskommuner och Församlingar. SOU 1978:32, Stockholm.

Strömberg, L., \& Westerståhl, J., 1984. The New Swedish Communes. Stockholm: Lerums Boktryckeri.

Tullock, G., 1959. Problems of majority voting. Journal of Political Economy, 67, 571-579.

Tyrefors Hinnerich, B., 2009. Do merging local governments free ride on their counterparts when facing boundary reform? Journal of Public Economics, 93, 721-728. 
Wångmar, E., 2003. Från Sockenkommun till Storkommun, En Analys av Storkommunreformens Genomförande 1939-1952 i en Nationell och Lokal Kontext. Acta Wexionensia 25, Doctoral Dissertation, Växjö: Växjö University Press.

Weingast, B., Shepsle, K., \& Johnsen, C., 1981. The political economy of benefits and costs: A neoclassical approach to politics. Journal of Political Economy, 89, 642-664. 